\title{
Assessment of Knowledge of Gingival Disease among the Patients attending Kantipur Dental College, Kathmandu
}

\author{
Dr. Sunita Khanal, ${ }^{1}$ Dr. Rosina Bhattarai, ${ }^{2}$ Dr. Bhageshwar Dhami, ${ }^{3}$ \\ Dr. G. Nagaraja Rao, ${ }^{4}$ Dr. Sujita Shrestha ${ }^{5}$ \\ 1,2Resident, ${ }^{4}$ Professor and Head, ${ }^{5}$ Lecturer, Department of Community Dentistry \\ ${ }^{3}$ Assistant Professor, Department of Periodontics \\ Kantipur Dental College, Kathmandu, Nepal
}

\begin{abstract}
Background: According to the National pathfinder survey of Nepal 2004, gingival disease is one of the most common oral diseases and if left untreated may lead to tooth loss.

Aim: To assess the knowledge of gingival diseases among the patients attending Kantipur Dental College, Kathmandu.

Materials and Methods: A cross sectional study was conducted among the patients attending Kantipur Dental College. The study was conducted from July to September 2016 with a sample size of 255. A specially designed questionnaire was used for data collection and SPSS version 20 was used for data analysis.

Results: Out of 255 participants, males were 127 in number and females 128. The questionnaire consisted of three domains and it was found that $67.1 \%$ had fair knowledge on basic knowledge of gingival diseases, $52.2 \%$ had fair knowledge on the etiology of disease and $52.2 \%$ had good knowledge on the treatment of gum diseases. While applying chi-square test, age and knowledge on all the three domains of disease were statistically significant whereas gender and knowledge were statistically insignificant.

Conclusion: This study showed that the level of knowledge among the studied population regarding gingival diseases was fair.

Key Words: Gingival disease, knowledge, questions
\end{abstract}

\section{INTRODUCTION}

Worldwide, dental disease is among the most widespread diseases. ${ }^{1}$ One of the most common disease among population is gingivitis and periodontitis and if left untreated may lead to tooth loss. ${ }^{2}$ Gingivitis is the reversible, non-destructive disease causing the inflammation of soft tissues without apical migration of the junctional epithelium and doesn't involve the loss of periodontal tissue. ${ }^{3}$ The inflammatory disease affecting the supporting tissues of the tooth is periodontitis. ${ }^{4}$ The risk factors for periodontal

\footnotetext{
Correspondence:

Dr. Sunita Khanal,

Department of Community Dentistry, Kantipur Dental College, Kathmandu, Nepal

email: khanal_sunita@hotmail.com

Citation

Khanal S, Bhattarai R, Dhami B, Rao GN, Shrestha S. Assessment of knowledge of gingival disease among the patients attending Kantipur dental college, Kathmandu. J Nep Soc Perio Oral Implantol. 2017;1:23-6.
}

disease are oral hygiene habits, smoking, diet, diabetes mellitus and various socio-economic factors. ${ }^{5}$ One of the fastest growing dental specialties is Periodontology and it offers cosmetic flare and regenerative health programs apart from the preventive and curative aspects of oral health. ${ }^{6}$ In the prevention of disease among children, adolescents and adults, oral health knowledge related to periodontal disease has a major role. ${ }^{2}$

According to the National Pathfinder Survey of Nepal 2004, presence of calculus was prevalent in all age groups which is indicative of poor oral hygiene. In this study, $48.3 \%$ of younger adults and $34.3 \%$ of older adults had the highest Community Periodontal Index score of $4-5 \mathrm{~mm}$ pockets. ${ }^{7}$ Systemic health including cardiovascular diseases, diabetes mellitus, preterm low birth weight and respiratory diseases are influenced by periodontitis. To improve the general health of the patients, health care professionals including dentists need to pay attention to periodontal diseases. Holistic approach between medical and dental professionals is required to treat patients. ${ }^{8}$ There is a lack of population 
based data on knowledge towards gingival and periodontal disease in Nepal, so this study will help us to improve the understanding of patients about periodontal diseases and reduce the myths of the general population about gingival and periodontal diseases and the treatment. The aims of present study were to assess the knowledge of gingival diseases among the patients attending Kantipur Dental College, Kathmandu, to compare the knowledge of gingival diseases among males \& females and to assess the difference in knowledge of gingival diseases with age.

\section{MATERIALS AND METHODS}

A cross sectional study was conducted among the patients attending Kantipur Dental College during the 3 months period i.e. July - September 2016. Ethical clearance was taken from the Institutional Review Committee. Required consent was taken from patients before their participation in the study. Purposive sampling technique was used for data collection. The sample size was calculated to be 254. Data collection was carried out by a single trained examiner. A specially designed questionnaire consisting of 26 questions was used which was categorized into three domains: (i) basic knowledge (ii) knowledge on the etiology of gum diseases and (iii) knowledge about treatment. The first domain consisted of questions related to basic knowledge. There were altogether twelve questions. The individuals scoring 0.1-4.0 was considered poor, 4.1-8.0 as fair and 8.1-12.0 as good. The second domain consisted of questions related to etiology of disease. There were altogether six questions. The individuals scoring 0.1-2.0 was considered poor, 2.1-4.0 as fair and 4.16.0 as good. The third domain had eight questions related to knowledge about the treatment of gingival disease. The scoring criteria was 0.1-2.6 as poor, 2.7-5.3 as fair and 5.38.0 as good. The questionnaire was designed in English and was translated in Nepali while asking questions for each participants by the examiner. For correct answer score +1 was given.

Inclusion criteria: Individuals of 20-60 years age group visiting Kantipur Dental College during the months of July

Table 1. Age and gender wise distribution of participants

\begin{tabular}{|l|c|c|c|}
\multirow{2}{*}{\multicolumn{1}{c|}{ Sex }} & \multicolumn{2}{|c|}{ Age in years } & \multirow{2}{*}{ Total } \\
\cline { 2 - 3 } & $\mathbf{2 0 - 3 9}$ & $\mathbf{4 0 - 6 0}$ & \\
\hline Male & $88(69.3 \%)$ & $39(30.7 \%)$ & $127(49.8 \%)$ \\
\hline Female & $79(61.7 \%)$ & $49(38.3 \%)$ & $128(50.2 \%)$ \\
\hline Total & $167(65.5 \%)$ & $88(34.5 \%)$ & 255 \\
\hline
\end{tabular}

- September 2016 and who were willing to participate in the study were enrolled.

Exclusion criteria: The individuals who did not give consent to participate in the study were not included.

Statistical analysis: SPSS 20 version software was used for data analysis. Chi-square test was used and $p \leq 0.05$ was considered statistically significant.

\section{RESULTS}

Out of total 255 participants, 127 were male and 128 were female. There were 88 males and 79 females in the 20-39 years' age group whereas 39 males and 49 females in 4060 years' age group (Table 1). Out of three domains, the first domain consisted of twelve questions related to basic knowledge. On interviewing, 52(20.4\%) had poor knowledge, 171(67.1\%) had fair knowledge and 32(12.5\%) had good knowledge (Figure 1). The second domain consisted of six questions related to etiology of disease and 35(13.7\%) people had poor knowledge, 133(52.2\%) had fair knowledge and 87(34.1\%) had good knowledge. (Figure 2) The third domain had eight questions related to knowledge about the treatment of gingival disease and it was found that $7(2.7 \%)$ had poor knowledge, 115(45.1\%) had fair knowledge and 133(52.2\%) had good knowledge (Figure 3). Chi square test was applied between the different variables to see the statistical difference. Gender and knowledge on all three domains was found to be statistically insignificant. (Table 2) but age and knowledge was found to be statistically significant. (Table 3)

\section{DISCUSSION}

Periodontal disease is an infrequently painful and infectious disease caused by an interaction between the bacteria and host. ${ }^{9}$ An essential prerequisite for health related behavior is oral health awareness and knowledge. ${ }^{10}$ Due to rapid growth in information technology, public are more aware about the various oral and general health problems. Knowledge on periodontal disease can help in the prevention of periodontal disease and healthcare professionals can act as the good

Figure 1. Pie chart showing the basic knowledge of disease

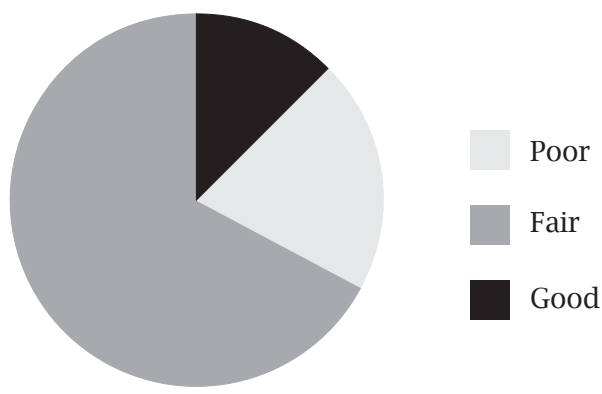


Figure 2. Pie chart showing the knowledge on etiology of disease
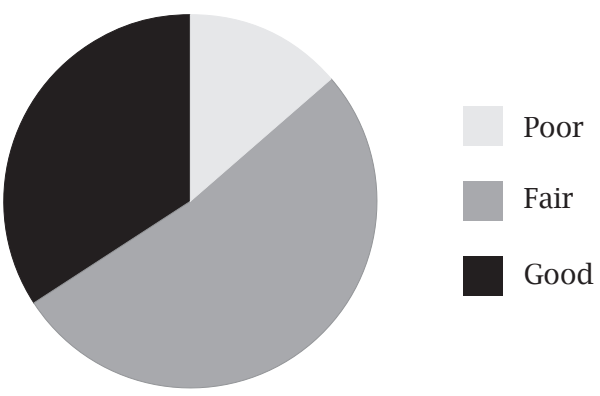

Figure 3. Pie chart showing the knowledge on treatment of disease

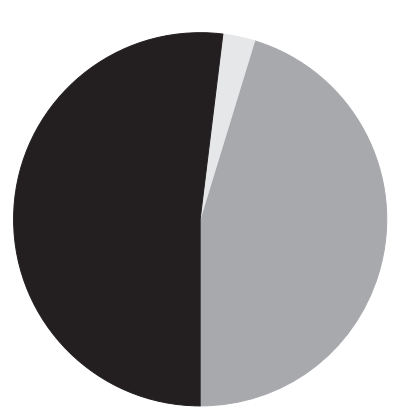

Poor

Fair

Good

Table 2. Gender wise comparison of knowledge of gingival disease

\begin{tabular}{|c|c|c|c|c|}
\hline & \multicolumn{2}{|c|}{ Gender } & \multirow{2}{*}{ Total } & \multirow{2}{*}{$p$ value } \\
\hline & Male & Female & & \\
\hline \multicolumn{5}{|c|}{ Basic Knowledge of disease } \\
\hline Good & 16 & 16 & 32 & \multirow{3}{*}{0.659} \\
\hline Fair & 88 & 83 & 171 & \\
\hline Poor & 23 & 29 & 52 & \\
\hline \multicolumn{5}{|c|}{ Knowledge on etiology of disease } \\
\hline Good & 39 & 48 & 87 & \multirow{3}{*}{0.233} \\
\hline Fair & 73 & 60 & 133 & \\
\hline Poor & 15 & 20 & 35 & \\
\hline \multicolumn{5}{|c|}{ Knowledge on treatment of disease } \\
\hline Good & 69 & 64 & 133 & \multirow{3}{*}{0.461} \\
\hline Fair & 56 & 59 & 115 & \\
\hline Poor & 2 & 5 & 7 & \\
\hline
\end{tabular}

Table no.3 Age wise comparison of knowledge of gingival disease

\begin{tabular}{|c|c|c|c|c|}
\hline & \multicolumn{2}{|c|}{ Age in years } & \multirow{2}{*}{ Total } & \multirow{2}{*}{$p$ value } \\
\hline & 20-39 years & 40-60 years & & \\
\hline \multicolumn{5}{|c|}{ Basic knowledge of disease } \\
\hline Good & 26 & 6 & 32 & \multirow{3}{*}{$0.036^{*}$} \\
\hline Fair & 113 & 58 & 171 & \\
\hline Poor & 28 & 24 & 52 & \\
\hline \multicolumn{5}{|c|}{ Knowledge on etiology of disease } \\
\hline Good & 64 & 23 & 87 & \multirow{3}{*}{$0.000 *$} \\
\hline Fair & 92 & 41 & 133 & \\
\hline Poor & 11 & 24 & 35 & \\
\hline \multicolumn{5}{|c|}{ Knowledge on treatment of disease } \\
\hline Good & 75 & 58 & 133 & \multirow{3}{*}{$0.006^{*}$} \\
\hline Fair & 87 & 28 & 115 & \\
\hline Poor & 5 & 2 & 7 & \\
\hline
\end{tabular}

source of knowledge providers to the general people. ${ }^{8}$ Many studies have been done to assess the knowledge of gingival and periodontal disease among the people. In this study, the basic knowledge on gingival disease was found to be fair among $67.1 \%$ of the participants, which is similar to other studies $^{9,11,12}$ but is in contrast to the study done by Bader $\mathrm{K}$
Al-Zarea ${ }^{2}$ and Taani. ${ }^{13}$ Knowledge on the etiology of disease was also fair among $52.2 \%$ of participants which is similar to the study conducted by Serino et al. ${ }^{14}$ but in contrast to the study conducted by Azodo and Umoh. ${ }^{15}$ Knowledge on the treatment of disease was good among $52.2 \%$ of the participants which is in contrast to the study conducted by 
Susmitha and Arjunkumar. ${ }^{5}$ Many studies have supported that periodontal disease are prevalent more in males compared to females. ${ }^{3,16}$ This is due to poorer oral hygiene, less positive attitude towards oral health, and dental-visit behavior among males than to any genetic factor. ${ }^{17}$ In this study, gender and knowledge level of the participants was found to be statistically insignificant which is similar to the study conducted by Taani ${ }^{13}$ and Vandana et al. ${ }^{18}$ but is in contrast to other studies. ${ }^{12,19,20}$ Periodontal disease increases with increase in age. ${ }^{4}$ This is due to change in host immunity against disease process and because of untreated cumulative effect of disease process over the period of time. ${ }^{3}$ The comparison of the age with level of knowledge of the participants was found to be statistically significant. Similar findings were reported from other studies. ${ }^{12,18}$

\section{CONCLUSION}

The examined population had significantly fair knowledge irrespective of their gender. More efforts should be made by dental professionals to improve the oral health knowledge of community so that higher health goals can be achieved.

\section{ACKNOWLEDGEMENTS}

I would like to thank Dr. Sujaya Gupta, MDS, Department of Periodontics, Kantipur Dental College.

\section{REFERENCES}

1. Srivastava R, Murali R, Shamala A, Yalamalli M, Kumar AV. Effectiveness of two oral health education intervention strategies among 12-year-old school children in North Bengaluru: A field trial. J Indian Assoc Public Health Dent. 2016;14(2):126-30.

2. Al-Zarea BK. Oral health knowledge of periodontal disease among university students. Int J Dent. 2013;2013:1-7.

3. Agarwal V, Khatri M, Singh G, Gupta G, Marya C, Kumar V. Prevalence of Periodontal Diseases in India. J Oral Health Comm Dent. 2010;4(Spl):7-16.

4. Rajkarnikar J, Acharya J. Prevalence and severity of periodontal diseases among Nepalese adults - a hospital based study. J Coll Med Sci. 2014;10(1):11-6.

5. Susmitha E, Arjunkumar R. Assessment of knowledge about periodontal disease among a group of health care professionals in Chennai city: A questionnaire study. Asian J Pharm Clin Res. 2015;8(6):101-5.

6. Pralhad S, Thomas B. Periodontal awareness in different healthcare professionals: A questionnaire survey. J Educ Ethics Dent. 2011;1(2):64-7.

7. Yee R, Mishra P. Nepal National Oral Health 'Pathfinder' Survey 2004. Kathmandu, Nepal: Oral Heal Focal Point, Ministry of Health, HMG Nepal, 2004.

8. Rajesh H, Boloor V, Rao A, Prathap S. Knowledge of periodontal disease among group of health care professionals in Yenepoya University, Mangalore. J Educ Ethics Dent. 2013;3(2):60-5.

9. Sawai MA, Bhardwaj A, Daing A, Jafri Z, Sultan N. Knowledge and attitude of medical practitioners towards periodontal diseases in New Delhi : A questionnaire based study. Ann Appl Biol Sci. 2015;2(4):121-6.

10. Hosadurga R, Tenneti S, Hegde S, Kashyap RS, Kumar A. Awareness, knowledge, and attitude of patients toward dental implants: A web-based questionnaire study. J Dent Implant. 2015;5(2):93-100.

11. Atarbashi F, Ahmad M, Ardakani H, Rashidi F, Arezoo M. Evaluation of Periodontal Health Knowledge, Attitude and Oral Hygiene Practice of Pregnant Women in Yazd in 2011. J. Periodontol Implant Dent. 2013;5(2):71-4.

12. Moghadam FA, Haerian A, Salami MS, Karbasi M, Tabatabayi RF, Vaziri F. Evaluation of Knowledge, Attitude and Practice between Periodontal Disease and Diabetes. J Commun Health. 2013;2(2):124-30.

13. Taani DQ. Periodontal awareness and knowledge, and pattern of dental attendance among adults in Jordan. Int Dent J. 2002;52(2):94-8.

14. Serino G, Wada M BK. Knowledge about risk factors associated with periodontal disease among patients referred to a specialist periodontal clinic. J Oral Sci Rehabil. 2016;2(2):58-63.

15. Azodo CC, Umoh AO. Periodontal Disease Awareness and Knowledge among Nigerian Primary School Teachers. Ann Med Health Sci Res. 2015;5(5):340-7.

16. Nordin MM, Rahman SA, Raman RPC, Vaithilingam RD. Periodontal status and oral health knowledge among a selected population of Malaysian type 2 diabetics. Sains Malaysiana. 2014;43(8):1157-63.

17. Alam MDN, Mishra P, Chandrasekaran SC. Gender Basis of Periodontal Diseases. Indian J Basic Appl Med Res. 2012;2(1):128-35.

18. Vandana K, Mahajan N, Savitha B. Knowledge, attitude, and practices of interdental aids among medical professionals in Davangere district, Karnataka. J Int Clin Dent Res Organ. 2015;7(1):39-43.

19. Bhatia A, Bains S, Singh M. To assess knowledge and awareness of North Indian population towards periodontal therapy and oralsystemic disease link: A cross-sectional survey. J Interdiscip Dentistry. 2013;3(2):79-85.

20. Gholami M, Pakdaman A, Jafari A, Virtanen JI. Knowledge of and attitudes towards periodontal health among adults in Tehran. East Mediterr Health J. 2014;20(3):196-202. 